\title{
Wessen Werte?
}

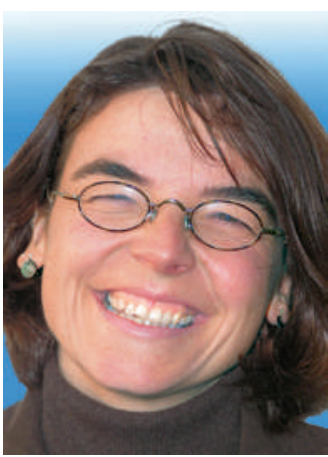

Christina Aus der Au

Lesen Sie hierzu auch den Beitrag auf Seite 929.

Die Provokation ist ein absolut legitimes (und meist auch lustvolles) Mittel, um das Bewusstsein des Provozierten zu erweitern. So bin ich den Herren Menuz und Roduit sehr dankbar, dass sie mich auf den Aufsatz von Liao, Sandberg und Roache aufmerksam gemacht haben. Dazu - Internet sei Dank! - auch gleich auf die hitzigen Diskussionen, die in angelsächsischen Blogs und Leserbriefseiten darüber geführt werden. Diese Auseinandersetzung hat mich vor allem in einer Überzeugung bestärkt: Man muss alles einmal denken dürfen. Und man muss auch - entsprechend vorsichtig formuliert - fast alles sagen dürfen. Vielleicht gibt es hier Ausnahmen, aber öffentlich denkschrankenlos darüber nachzudenken, wie man das Problem der Klimaerwärmung angehen könnte, gehört meines Erachtens nicht zu diesen Ausnahmen.

Auch dann nicht, wenn darüber nachgedacht wird, ob man dafür am Menschen herumschrauben solle. Statt der moralischen Appelle, der neuen und nachhaltigen Technologien und Märkte und statt der grossflächigen Einwirkung auf den $\mathrm{CO}_{2}$-Kreislauf nun also der gezielte Eingriff in den Urheber des Problems, den Menschen. Eigentlich eine Methode, die vielerorts mit gutem Erfolg praktiziert wird, gemäss dem Verursacherprinzip das Übel bei der Wurzel zu packen. Nämlich beim unersättlichen Fleischhunger, bei der wachsenden Ausdehnung sowohl der Spezies als auch des Individuums Mensch und beim menschlichen Egoismus und der mangelnden Empathiefähigkeit.

\section{«Wer definierte denn hier die Notwendigkeiten? Und wer profitierte von dieser Entwicklung?»}

* PD Dr. theol. Christina Aus der Au ist an der Abteilung Systematische Theologie/ Dogmatik der Universität Basel tätig und Mitglied der Redaktion Ethik der Schweizerischen Ärztezeitung.
Wenn man dies alles beeinflussen könnte, gezielt, relativ kostengünstig und flächendeckend, und wenn die Menschen dann zahlenmässig weniger sind, weniger essen und weniger gierig sind - was spräche dann dagegen, das $\mathrm{CO}_{2}$ auf diese Weise zu reduzieren?

Was - ausser dem erschreckenden Gedanken, dass hier auf unheimlichste Art und Weise in das Wesen des Menschen eingegriffen würde? Dass hier die Freiheitsrechte des Individuums mit Füssen getreten und dem Wohl eines Ganzen geopfert werden sollen? Dass nicht am menschlichen Körper, sondern an seiner Seele herumgebastelt würde? Zudem: Wer definierte denn hier die Notwendigkeiten? Und wer profitierte von dieser Entwicklung?

Das Spannende an diesem Gedankenexperiment und mehr will es ja eingestandenermassen zunächst gar nicht sein - ist, dass dabei sichtbar wird, was tat- sächlich auf dem Spiel steht. Einerseits die drohende Klimakatastrophe und mit ihr Dürre, Stürme, Überschwemmungen, Land- und Heimatverlust, Krankheiten und immense Kosten. Andererseits Werte wie Selbstbestimmung, Individualität, Menschenrechte, Demokratie, persönliche Integrität, Gerechtigkeit und Freiheit.

Eine simple Entscheidung zwischen dem Utilitarismus, dem grösstmöglichen Nutzen für die grösstmögliche Anzahl von Beteiligten, und einer Pflichtenethik, unverhandelbare Werte und Normen, würde man meinen.

Aber - wer verteidigt denn diese aufklärerischen und liberalen Prinzipien? Sind das nicht vor allem wir, die gut ver- und abgesicherten Festlandeuropäer und -amerikaner, die nicht von der Scholle leben, sondern Nahrungsmittel aus aller Welt importieren und deren Häuser weder im Meer versinken noch vom Hurricane davongetragen werden? Und wer auf der anderen Seite droht, seine Lebensgrundlagen zu verlieren, und pfeift in dieser Situation wahrscheinlich auf $10 \mathrm{~cm}$ mehr Körpergrösse, eine «natürliche» Gen- und Hormonausstattung und einen Geschmackssinn für Fleischgenuss, den er oder sie sich wahrscheinlich sowieso nicht leisten kann?

Ist das Festhalten an den hehren Werten und Prinzipien in dieser Frage nicht zum Luxus geworden, den wir uns nur leisten können, weil wir von der Klimaerwärmung nicht im gleichen Masse betroffen sind wie Bewohner und Bewohnerinnen von Inselstaaten und armen Agrarnationen? Wäre es nicht an der Zeit, auch darüber nachzudenken, wie wir unseren Teil zur $\mathrm{CO}_{2}$-Reduktion leisten könnten? Nämlich wenn es offenbar freiwillig nicht geht, wie das Schicksal der Konventionen, Mandate und Protokolle seit Rio 1992 zeigt, wenigstens freiwillig verpflichtend - indem wir nämlich zustimmen würden, unsere widerstrebende Menschlichkeit zum Nutzen der Menschheit per gen- und hormontechnischen Eingriff nachhaltiger zu machen.

So könnte man auch mit Fug und Recht ethisch argumentieren. Und doch bleibt mir diese hartnäckige Stimme, die darauf beharrt, dass mit solchen Eingriffen in den Menschen etwas Hohes und Tiefes verloren ginge. Nämlich die Herausforderung, nicht nur Homo Faber in einer Welt zu sein, die nach Belieben manipuliert werden kann, sondern auch hörender, staunender, liebender Homo sapiens, der nicht nur viel weiss, sondern auch weise mit diesem Wissen umzugehen weiss.

Christina Aus der $\mathrm{Au}$ * 